\title{
Splinter Removal with the Aid of Ultrasonography: A Case Report
}

\author{
C K Lee, MS (Ortho) , T Sara Ahmad*, FRCS, BJ Abdullah**, FRCR \\ Department of Orthopaedic \& Traumatology, Hospital Sungai Buloh, Selangor, Malaysia \\ *Department of Orthopaedic Surgery, University Malaya Medical Centre, Kuala Lumpur, Malaysia \\ **Department of Biomedical Imaging, University Malaya Medical Centre, Kuala Lumpur, Malaysia
}

\begin{abstract}
Splinter or foreign body removal from the hand and foot is a common occurrence. Usually only the deep seated, broken or missed splinters are referred to the surgeon for removal. Unless the object is radio-opaque, plain radiograph will not give any useful information, hence removal can sometimes be very difficult and traumatic. We are reporting a case where a radiolucent splinter was removed with the aid of ultrasonography. This modality can help to localize a splinter at the pre and intra-operative period, minimizing amount of exploration and time of operation.
\end{abstract}

Key Words:

Splinter, Ultrasonography

\section{INTRODUCTION}

Foreign body implantation is a common occurrence in both children and adults. Large ones are easily seen and removed either by the patient themselves or by a general practitioner. Foreign bodies which are embedded deep in the soft tissue, incompletely removed or too small for easy removal are referred to a surgeon for removal. In many cases, splinters and other foreign bodies were overlooked in initial evaluation of soft tissue wounds in the emergency room. The patient may come back with local soft tissue infection and complain of foreign body sensation ${ }^{1}$. Foreign body removal can be aided by image intensification, if they are radio opaque. However, radiolucent splinters like wood, for instance, are not easy to locate. The injury usually occurs at the extremities. The sole and palm are the two commonest sites. We would like to report a case where a wooden splinter was removed with the aid of ultrasonography (USG).

\section{CASE REPORT}

A 43-years-old man slipped and fell during a Tai-Chi session. His left hand landed on wooden Chinese tea stirrers, which broke on impact. He sustained a laceration wound on his left palm. He sought treatment from a private clinic. Dressing was done; tetanus prophylaxis was given along with antibiotics and anti-inflammatory medication. About a week later, he complained of foreign body sensation and came to the emergency unit to seek treatment. Routine physical examination and plain radiography did not reveal any evidence of foreign body, but the patient insisted that he had a foreign body in his palm. Debridment of the infected wound and attempted removal of foreign body was performed in the minor operation theatre under local anaesthesia, but nothing was found.

During subsequent consultation, USG was suggested by a radiologist, as a cheaper alternative to magnetic resonance imaging (MRI). A 5-7.5 MHz linear probe was used and the investigation revealed an echo compatible with a wooden fragment of about $10 \mathrm{~mm}$ in length (Figure 1). Surgery under local anaesthesia with tourniquet was scheduled one week later. An incision was made over the area of maximum tenderness, since there was no skin marking during USG. However, the foreign body could not be found. After about an hour of exploration, the same radiologist was requested. Using an ultrasound machine with a $5-7.7 \mathrm{MHz}$ linear probe covered in a sterile plastic cover, the foreign body was easily located and marked with an $18 \mathrm{G}$ needle. The wooden splinter was then located and removed within the next 10 minutes. The splinter measured $12 \mathrm{~mm}$ in length and $2 \mathrm{~mm}$ in diameter (Figure 2). The wound was cleaned and closed with nylon 3-O . Wound healing was uneventful.

\section{DISCUSSION}

Splinter injury is very common and the usual sites are palm of the hand and sole of the foot ${ }^{1}$. The splinter can be found superficially, in the subcutaneous tissue or even deep in the muscle. Localization of embedded foreign body may prove to be very difficult and exploration under regional or general anaesthesia with the use of tourniquet should be performed whenever possible.

Wood, glass and metallic splinters are the most common retained foreign bodies ${ }^{2,3}$. If left in the body, they will cause

Corresponding Author: Lee Chee Kuan, Dept. of Orthopaedic \& Traumatology, Hospital Sg. Buloh, 47000, Sungai Buloh, Selangor D.E. Email: sbanlck@yahoo.com 


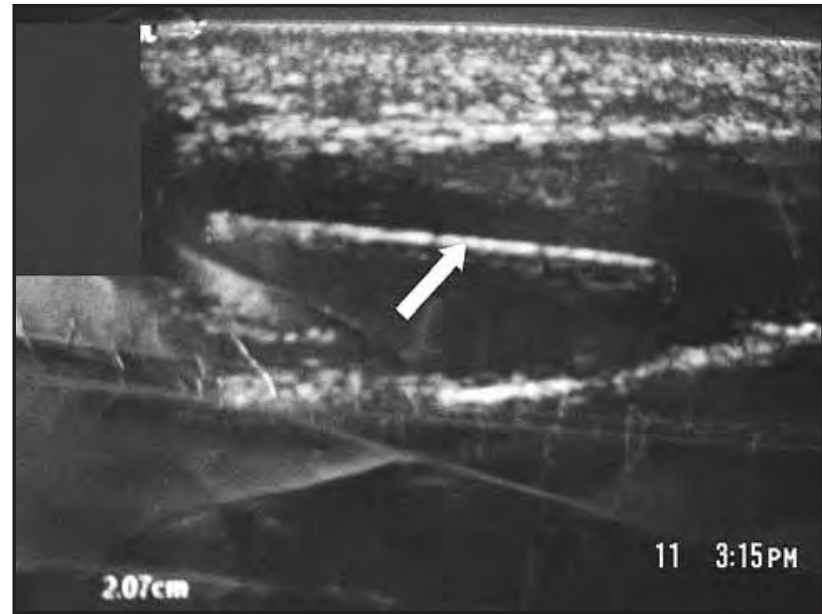

Fig. 1: Ultrasonography showing sinter eho in the palm (arrow).

inflammatory reaction that may lead to either infection with abscess or granuloma formation. Wood, thorns, spines and other vegetable foreign bodies tend to elicit a strong immune response, whereas glass, metal and plastic are relatively inert ${ }^{3}$.

Retained foreign bodies in the soft tissue of the extremities that were initially overlooked and discovered later are unfortunately common. A deeply situated foreign body can be easily missed during initial physical examination especially if the patient presents late. Plain radiographs can be used to detect a radio-opaque foreign body, for example metal splinters and some types of glass. Wood and vegetative materials on the other hand are usually radiolucent. Unfortunately, these radiolucent materials are usually more prone to cause an inflammatory reaction and infection ${ }^{4}$. Computed tomographic (CT) scanning and magnetic resonance imaging (M.R.I.) can detect many foreign bodies that may be missed by plain radiograph. Cost effectiveness and time factor are the two main reasons why they are not routinely used. USG can be available before and during surgical exploration. A 7.5 $\mathrm{MHz}$ probe is usually

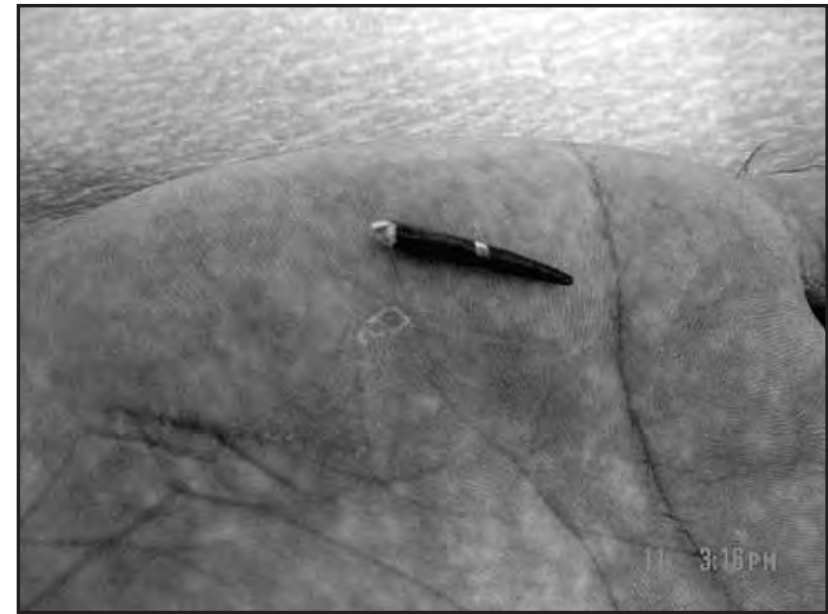

Fig. 2: The splinter indicating its location in the palm.

used to detect small, superficial objects, whereas a $5.0 \mathrm{MHz}$ probe is used for larger and deeper objects. USG can provide important information on the depth, size and shape of the foreign body as well as its anatomical relationship with the surrounding structures. It usually appears as a hyper-echoic focus, sometimes surrounded by hypo-echoic halo representing edema, abscess or granulation tissue. The ultrasound machine is portable and can be easily used intra operatively just by covering the probe with sterile material. These are the most distinct advantages over CT scan and MRI. The operative time can be shortened and the risk of iatrogenic tissue damage is reduced. The main disadvantage is that an experienced radiologist it required to perform and interpret the findings.

USG is a useful diagnostic modality and therapeutic adjuvant in the management of wooden splinter or other foreign in the extremities. Exploration should be performed under regional or general anaesthesia with tourniquet to provide a better operative view. 


\section{REFERENCES}

1. Blakstein A, Cohen I, Heuman Z, Salai M, Heim M, Chechick A. Localised, detection and guided removal of soft tissue foreign bodies in the hands using sonography. Arch Orthop Trauma Surg 2000;120:514-17

2. Chan C, Gohar A, Salam. Splinter Removal. American Family Physician.; June 2003; 6 (12): 2557-62

3. Smoot EC, Robson MC, Ac. Management of foreign bodies injuries in hand. Ann Emerg Med. 1983;12:434-7

4. Hung YT, Hung LK, Griffith JF, Wong CH, Ho PC. Ultrasound for the detection of vegetative foreign body in hand. Hand Surgery. 2004; 9(1): 83-7. 